\title{
Cytosolic Glutathione S-transferase in Bacteria: A Review
}

\author{
Dayyabu Shehu ${ }^{1,2 *}$, Nasiru Abdullahi, ${ }^{1,2}$, Zazali Alias ${ }^{1 * *}$ \\ ${ }^{1}$ Department of Biochemistry, Institute of Biological Sciences, University of Malaya, Kuala Lumpur, Malaysia \\ ${ }^{2}$ Department of Biochemistry, Bayero University, Kano, Nigeria
}

Received: 18 October 2017

Accepted: 10 February 2018

\begin{abstract}
Cytosolic glutathione S-transferase in bacteria possesses the biochemical capacity to degrade various classes of organochlorine pollutants in the environment in addition to their primary role of defending the organism from a wide range of endobiotics and xenobiotic substrates. Furthermore, the ability of different classes of cGST to recognize a wide repertoire of substrates due the variability in the substrate binding site of the enzymes makes them well suited for bioremediation purposes. cGSTs act as dehalogenases promoting a rapid degradation of various organochlorine compounds. Dehalogenation served as the primary mechanism for detoxification of various organochlorine compounds, making them vulnerable to attack by other degradative enzymes. However, despite their potential and advantage of wide substrate specificity, cGSTs have not been exploited for bioremediation purposes. In this review, we described the various cGST classes in bacteria and their phylogenetic relationships. Furthermore, the review reiterated that cGSTs in bacteria are involved in dehalogenation reaction, and this property can be harnessed for bioremediation of a diverse class of organochlorine pollutants as they currently represent the largest class of pollutants in the environment.
\end{abstract}

Keywords: cytosolic, glutathione S-transferase, bacteria, dehalogenation, bioremediation

\section{Introduction}

Glutathione S-transferases (GSTs) constitute a family of ubiquitous enzymes that play a vital role in detoxifying a diverse class of exogenous and endogenous electrophilic substrates [1]. GST catalyzes the conjugation reaction between the electrophilic center of various classes of substrates and the sulfur atom of reduced glutathione to generate water-soluble glutathione conjugate that can be easily excreted [2]. Furthermore, GSTs were also

*e-mail: dshehu@siswa.um.edu.my

**e-mail: alias@um.edu.my found to bind several other exogenous and endogenous compounds in a non-catalytic fashion, thereby helping in various cellular processes [3]. They occur in almost all living organisms, including plants, animals, fungi, and bacteria [4].

Four different classes of GSTs were identified in bacteria, namely cytosolic (cGSTs), mitochondrial-, microsomal-, and bacterial-specific fosfomycin-resistance protein [5]. Among the various GST classes identified in bacteria, cytosolic GSTs (cGSTs) represent the largest class of known GSTs. Furthermore, in addition to their functional role of defense against various products of oxidative stress, the cGSTs in bacteria were known to occur in several degradative pathways, indicating their 
importance in the bioremediation of a diverse class of pollutants [6]. Advances in gene sequencing techniques also continued to provide insight into new classes of cGSTs in bacteria with novel functions. Currently, seven different classes were already identified in bacteria, with some of them playing a valuable role in the biodegradation of several classes of pollutants [5, 7-9].

The population explosion and industrialization in the agro-economic sector has resulted in tremendous increases in the use of chemicals that are detrimental to human health and the environment [10-11]. Organochlorine compounds represent the largest group of chemicals used either industrially or as pesticides. However, they also represent the most noxious and recalcitrant compounds in the environment. Removal of halogen from the various organochlorine compound by dehalogenases is considered to be one of the key mechanisms for reducing toxicity and persistence, and also helps in maintaining the halogen biogeochemical cycle [12]. Various isoforms of cytosolic GSTs from bacteria have shown a promising application in the bioremediation of a diverse class of organochlorine compounds. However, the study of bacterial cGST is still at an infant stage compared to many other enzymes used for bioremediation purposes. This review looks at an overview of the currently documented studies on cytosolic GSTs in bacteria, including current classification and phylogenetic relationships. The review further reiterated on the potential application of many classes of cGST in the bioremediation of several organochlorine compounds. Furthermore, due to diverse catalytic function and wide substrate specificity displayed by various classes of GSTs, we solely focused on dehalogenation functions catalyzed by the cytosolic GSTs. Where known, the mechanism underpinning the dehalogenation reaction against several substrates was also explored. Different organochlorine compounds that are substrates for bacterial GSTs were analyzed for their toxicity and biodegradation, and the potential application that various classes of bacterial cytosolic GSTs could offer in the bioremediation of these pollutants. Suggestions for improvement were also discussed in the conclusion section.

\section{Methods}

\section{Study Selection}

Several electronics databases (ISI web of science, CINAHL, MEDLINE, EMBASE) were searched for English-language articles reporting glutathione S-transferase. However, these articles were filtered in order to include only the articles that fulfilled the inclusion criteria. We included studies in which (1) the main focus was on glutathione S-transferase in bacteria; (2) among the various classes of GSTs in bacteria, the core emphasis was on cytosolic GSTs, so therefore only articles reporting the cGST in bacteria were selected; and (3) considering the diverse catalytic functions of cytosolic GST on different classes of substrates, the core emphasis was given to dehalogenation of organochlorine compounds as they represent the largest group of pollutants in the environment.

Excluded articles were those in which the study was on glutathione S-transferase in other specie (plants, mammals, fungi, and insects). However, a literature search was also performed on those articles reporting the toxicity of various organochlorine pollutants.

\section{Phylogenetic Analysis}

Various representatives of GST classes from both prokaryotic and eukaryotic organisms were used to investigate the evolutionary history and phylogenetic analysis of bacterial cytosolic GSTs. The amino acid sequences of various GST representatives was obtained from databases such as the National Center for Biotechnology Information (NCBI). Multiple sequence alignment was produced using CLUSTAL W12 [13]. The evolutionary history was inferred using the neighbor-joining method [14]. The tree is drawn to scale, with branch lengths in the same units as those of the evolutionary distances used to infer the phylogenetic tree. The evolutionary distances were computed using the Poisson correction method and are in the units of the number of amino acid substitutions per site [15]. The analysis involved 34 amino acid sequences. All positions containing gaps and missing data were eliminated. 133 positions were included in the final dataset. Evolutionary analyses were conducted in MEGA6 [16].

\section{Results and Discussion}

\section{Structure and Phylogenetic Relationship of Cytosolic Glutathione S-transferases in Bacteria}

The evolution of glutathione S-transferase in bacteria was thought to occur four times in an independent manner, yielding four different classes: cytosolic, mitochondrial, microsomal, and bacterial fosfomycinresistant proteins [5, 17]. Each of these classes contained members that are evolutionarily related to carrying out different functions, and some possessing overlapping functions between one class and another. In bacteria, cytosolic GSTs contained the largest family members so far discovered. They are dimeric proteins with average molecular weight of 25,000 Da. They either form homo or heterodimer with their subunits derived from the same class of isoenzyme [18]. Each monomer has a $\mathrm{G}$-site and $\mathrm{H}$-site located at the $\mathrm{N}$ - and $\mathrm{C}$-terminal domains, respectively, which functions in the binding of co-substrate glutathione (GSH) and several classes of hydrophobic substrates, respectively [19]. The G-site is an essential pocket that is specific for GSH and was found to be relatively conserved among all GST classes. The $\mathrm{C}$-terminal contains the $\mathrm{H}$-site and, unlike 
the G-site, it varied among GSTs, which gives flexibility for different classes of GST to recognize a diverse range of both endogenous and exogenous substrates [20]. Catalytic active monomers have not been observed in GSTs, and whether the formation of dimers is coupled to enhancing the activity of the enzyme is a subject of investigation [18].

In bacteria, in addition to the previously known cytosolic beta, Chi, Zeta, and Theta classes, three additional classes of Rho, Eta, and $\mathrm{Nu}$ were recently discovered [7-9, 17]. One major criterion for classifying cytosolic GSTs is the use of percentage sequence similarity, which is generally agreed that proteins which shared $40 \%$ and above, the sequence similarity belongs to the same class, while those with less than $20 \%$ are classified into a different class [21]. Other factors such as crystal structure similarity, kinetic properties, and immunological features were also taken into consideration to fully classify a cGST into a particular class [19]. It is worth noting that despite the extensive sequence variation that exists between various GST classes, all the classes were able to maintain a structural scaffold that ensures the integrity of glutathionecatalyzed conjugation reaction. A typical example is seen in four different GST classes whose crystal structures were determined: a beta class GST from Proteus mirabilis, two GSTs from E. coli, and human theta class GST [5]. These GSTs shared less than 20\% sequence similarity between their amino acid sequences, yet they all maintained a specific structural scaffold that ensured that the integrity of GST-catalyzed conjugation reactions is not compromised [22].

A phylogenetic analysis of cytosolic GSTs from bacteria (prokaryotic) and other eukaryotic representatives (mammals, insects, and plants) is shown in Fig. 1. The phylogenetic tree showed the various

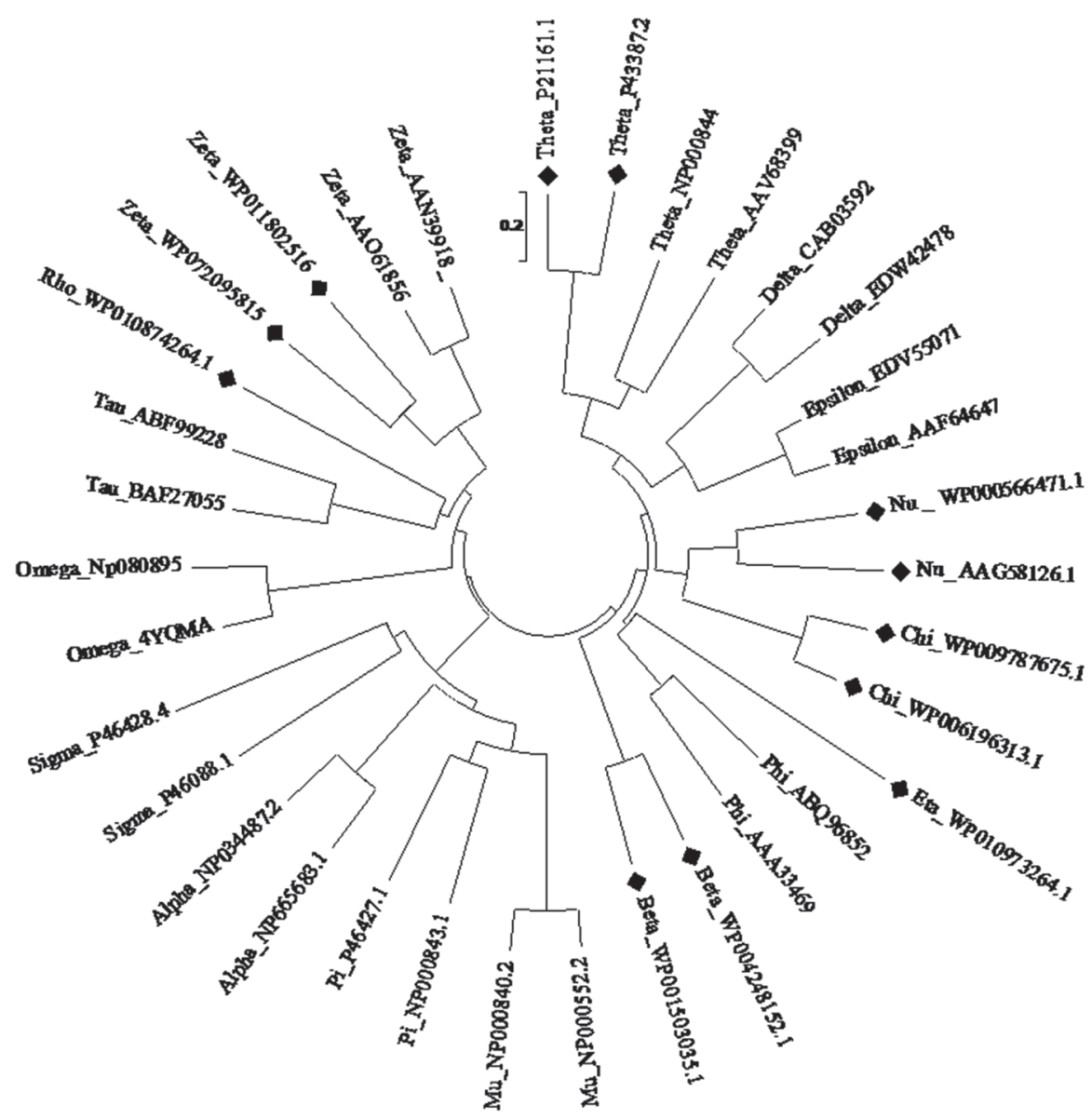

Fig. 1. Evolutionary relationship between representatives of eukaryotic and prokaryotic cytosolic glutathione S-transferases. P21161 Methylobacterium extorquens DM4, P43387 Methylophilus leisingeri, NP000844 Homo sapiens, AAV68399 Aedes aegypti, CAB03592 Anopheles gambiae, EDW42478 Drosophila sechellia, EDV55071 Drosophila erecta, AAF64647 Drosophila melanogaster, WP_000566471 Proteobacteria, AAG58126 Escherichia coli O157:H7 strain, WP_009787675 Lyngbya sp. PCC 8106, WP_006196313 Nodularia spumigena, WP_010973264 Agrobacterium tumefaciens, ABQ96852(Solanum commersonii), AAA33469 (Zea mays), WP_004248152 (Proteu mirabilis), WP_001503035 (Escherichia coli), NP_000840 (Homo sapiens), NP_000552 (Homo sapiens), NP 000843 (Homo sapiens), P46427 (Onchocerca volvulus), NP 665683 (Homo sapiens), NP 034487 (Mus musculus), P46428 (Anopheles gambiae), P46088 (Nototodarus sloanii), 4YQM_A Homo sapiens, NP_080895 Mus musculus, BAF27055 Oryza sativa Japonica Group, ABF99228 Oryza sativa Japonica Group, WP_010874264 Synechocystis sp. PCC6803, AAN39918 (Capsicum annuum), AAO61856 (Malva pusilla), WP 011802516 Polaromonas naphthalenivorans, WP_072095815 E-coli. The bold-pointed sequences represent various classes of prokaryotic GSTs and their distribution. 
distribution of the cytosolic GSTs into different classes consistent with their evolutionary relationship. Two classes, beta and zeta, were known to have eukaryotic counterparts and can be seen lying next to each other. This indicates the close relationship that existed between the eukaryotic and prokaryotic GSTs. Four out of the five classes; eta, nu, chi, and theta were lying close to one another and from the same cluster, which suggests the possible evolutionary relationships between those classes. Eta class GST was found lying very close and in the same cluster with a plant's phi class GST. This is not surprising as structural analysis of Eta class GST showed a strong resemblance to that of Phi class GST [20]. The newly discovered rho class GST can be seen lying in-between zeta and plants Tau class GSTs. This might indicate a possible evolutionary relationship between zeta and either tau or zeta class GSTs, though the crystal structure of the class was not available.

\section{Classification of cGST in Bacteria}

\section{Beta Class GST}

The prototype of beta class GST was first identified from Proteus mirabilis after carefully analyzing that the GST display certain structural and biochemical properties that differentiates it from other known GST classes [23]. Beta class GST was found to occur only in bacteria, and currently four crystal structures of beta class GST belonging to different organisms have already been analyzed [18]. The overall crystal structures in all four classes consist of an N-terminal domain that resembles the thioredoxin-like protein fold. The C-terminal domain was found to be all helical and is separated by a short linker. In addition, a unique structural motif discovered only in beta class GST was also identified from OaGST [23]. This motif was found at the G-site and it consists of a network of hydrogen bondings that function to zipper the end of the $\mathrm{C}$-terminal domain and the starting helix of the thioredoxin-like domain. Beta-class GSTs have characteristic reactivity with 1-chloro-2,4- dinitrobenzene (CDNB), the existence of cysteine at the glutathione binding site, and their ability to be separated using GSH matrix [23]. Furthermore, they were found to conjugate antibiotics, therefore helping in conferring antibiotic resistance to the organisms [24].

\section{Theta Class GST}

Theta class GSTs in bacteria were first identified from facultative methylotrophic bacteria Methylobacterium sp. Strain DM 11 [25]. Later, the enzyme was also identified from another strain called Methylobacterium sp. DM 4 [26]. Theta class GST has dichloromethane dehalogenase (DCM) activity and they were referred to as DCM dehalogenases. Bacteria that possessed DCM dehalogenase could single-handedly break down the dichloromethane for subsequent energy generation.
The enzyme lacks reactivity with DCNB and does not bind to the GSH affinity matrix [5, 27]. Several other DCM dehalogenases were also identified from different bacterial strains. Analysis of sequence variations among different DCM dehalogenases revealed highly conserved sequences that affect catalytic properties of the proteins [28].

\section{Zeta Class GST}

Zeta class was first identified while studying the evolution of GST through sequence alignment study [29]. The enzyme was found to be distributed in many species, including humans, plants, and bacteria. The distinguishing characteristic of zeta class GSTs is that they possess tetrachlorohydroquinone (TCHQ) dehalogenase and isomerase activities [30]. They were also found to have dichloroacetate dechlorinating activity [31]. The N-terminal domain of zeta class GSTs is uniquely identified by the presence of a signature motif; SSCX(W/H)RVRIAL and RSSASYRVRIAL for eukaryotic and prokaryotic sequences, respectively [32]. The result of sequence alignment studies of various GST-classes also showed that the first serine residue in these motifs is highly conserved and is analogous to the catalytically essential serine found in theta, phi, and delta classes [32-33]. Two distinct groups of zeta class GSTs were observed based on the analysis of more than 200 similar sequences. The first group is found in eukaryotic sequences and they contained the first serine and a cysteine residue in the motif partnered by glutamine at the N-terminal domain that function in the stabilization of the GSH. This group is usually found in MAAI and tetrachlorohydroquinone dehalogenases (TCHQ-DH) [34]. The second group is usually found in prokaryotes, and they contained serine but in place of cysteine, a polar side chain usually (Ser, Thr, or Ala) partnered with histidine 104 at the N-terminal domain are present [35]. Even though this second group was found to lie within the clusters of gene involved in tyrosine metabolism, the lack of cysteine residue suggests that they are not required for MAAI activity. This group was found to be predominantly MPIs with alanine contributing to $>50 \%$ of the residue at that position. In this second group, the residues RS----RVRIAL were also shown to be $>85 \%$ conserved with the first arginine functions in substrate recognition [32, 34-35].

\section{Chi Class GST}

Chi class GSTs are among the newly discovered cytosolic GSTs from bacteria after beta, zeta, and theta classes. This class was first identified from cyanobacteria called Synechococcus elongates PCC 6301 and Thermosynechococcus elongates BP-1 [36]. The proteins were found to exhibit low sequence similarity to other known GST classes. Although crystal structure of any of the members was not determined, online structural prediction using other known GST classes showed 
that the enzyme displayed typical structural features that were found to be present in other cytosolic GSTs. This includes the presence of Pro53, Ile 68 identified in what is called motif I and the N-capping box containing "Ser/Thr-Xaa-Asp" residues, which played a role in the folding of GSTs. Further secondary structural analysis predictions using known crystal structures of other GST classes also showed that chi class adopts the usual $\beta \alpha \beta \alpha \beta \beta \alpha$ and all helical structures found in $\mathrm{N}$ and C-terminal domain of all GSTs, respectively. However, one distinguishing feature of this class of GST is the absence of essential cysteine residue found in beta class GST, though other potential candidates such as Ser and Tyr are present around the N-terminal position, which might fulfill the function. The GST has distinguishing characteristics of exhibiting activity toward isothiocyanates (a plant-based compound that acts as a defensive mechanism during injury or inversion by pathogens). The enzyme was also found to exhibit moderate activities against a wide range of GST standard substrates [36].

\section{Eta Class GSTS}

The GST termed Eta class was first identified from a pathogenic soil bacterium Agrobacterium tumefaciens C58. The protein was found to exhibit very low sequence similarity with all known cytosolic GST classes. It was designated as (Atu GSTH1-1) and called Eta class GST. The crystal structure of Eta class GST was determined in complex with S-(P-nitrobenzyl)-glutathione. The structure showed a typical overall fold of GSTs with N-terminal domain resembling the thioredoxinlike protein fold and an all $\alpha$-helical segment in the C-terminal domain. Comparison of the crystal structure of Atu GSTH1-1 with the crystal structures of other known cGSTs showed that it closely resembles YfcG; a $\mathrm{Nu}$ class GST from E. coli. One special feature that was observed in Atu GSTH1-1 is the absence of essential Tyrosine, Cysteine, or Serine residues at the glutathione binding site of the protein. These residues were found to play an essential role in the binding and activation of GSH in various GST classes. However, site-directed mutagenesis studies showed that Phe 22, Ser 25, Arg 34, and Arg 187 contributed significantly to catalysis. The enzyme was found to show significant activity toward aryl halides as well as strong peroxidase activity toward organic hydroperoxides [8].

\section{Rho Class GSTS}

This class of cytosolic GST was first reported from a cyanobacterium Synechocystis PCC 6803. The enzyme was found to display very low sequence similarity, showing the highest similarity of $21 \%$ with representatives from zeta, theta, and alpha classes. Based on percentage sequence similarity, the enzyme was designated as rho class GST. Furthermore, while the average molecular weight of cytosolic GSTs is around
$25 \mathrm{KDa}$, this protein was found to have a molecular weight of about 30KDa. Biochemical characterization showed that the enzyme has strong dehalogenase activity toward dichloro-acetate and glutathione-dependent peroxidase activity [7].

\section{Nu Class GSTS}

$\mathrm{Nu}$ class GST was first identified from Escherichia coli after observing unique structural and catalytic properties not previously seen in other GST classes [9, 37]. Two representative members currently identified are designated as YfcG, also known as (GST N1-1) and YghU and also labeled as (GST N2-2). YfcG was found to show very low activity with standard GST substrate 1-chloro-2,4-dinitrobenzene (CDNB). The peroxidase activity of the enzyme was only detected with cumene hydroperoxide, but not with other peroxides. Structurally, YfcG was found to possessed typical GSH transferase features with N-terminal domain resembling that of thioredoxin-like proteins and all $\alpha$-helical domain at the C-terminal part of the protein. Crystal structure of YfcG was grown in the presence of reduced glutathione (GSH), but surprisingly an oxidized glutathione GSSG was found occupying the active site between the two subunits of the dimer. The disulfide bond was also found to be on the surface of the protein, similar to what was observed in glutaredoxins and thioredoxins. Although his suggests that the protein might be involved in oxidoreductase activities, no cysteine residue is present at the active site of the protein. This further shows that the sulfhydryl groups are not involved in the redox chemistry of the reaction. Furthermore, this suggests a unique disulfidebond reductase activity from the members of the YfcG family [9].

The crystal structure of YghU reveals a somewhat interesting and completely new phenomenon with regards to GSH binding. The enzyme exhibited an unusual behavior by binding to two molecules of GSH in each of its active sites: one tight and one weak binding. The binding behavior observed is consistent with their kinetic behavior, which suggests either negative cooperativity or differences in the affinity of the two GSH molecules to their respective active sites. Overlay of the two crystal structures from YfcG and YghU showed very close similarity and even in the superposition of the two GSH from YghU and the GSSG from YfcG. Another interesting scenario observed in the crystal structures of both YfcG and YghU is the presence of threonine and arginine residues at the opposite subunits of their crystal structures. The threonine residue interacts with the first GSH molecule in YfcG and GSSG in YghU, while the arginine residue interacts with the second molecules of GSH and GSSG in $\mathrm{YfcG}$ and YghU, respectively. Just like YfcG, the YghU enzyme failed to show transferase activities using most standard GST substrates. However, it did show modest peroxidase activities toward several organic hydroperoxides [37]. 


\section{Role of Bacterial cGSTs in the Dehalogenation of Organochlorine Pollutants}

Many of these classes of bacterial GSTs showed a promising application as dehalogenases, thereby helping in the bioremediation of several organochlorine pollutants. They catalyze reductive dehalogenation (also termed thiolytic dehalogenation), in which a chlorine atom from the substrate is replaced by the thiol group from the reduced glutathione and forms a glutathione conjugate [38]. Among the various classes of cytosolic GSTs discovered in bacteria, four different classes theta, beta, rho, and zeta - were found to possess the dehalogenation function against various substrates 7, 39-40]. This signifies the functional role of bacterial GSTs not only in the defense against the product of oxidative stress but also in the detoxification of a diverse range of pollutants, thereby helping in cleaning the environment.

\section{Dehalogenation of Pentachlorophenol}

Pentachlorophenol is a polychlorinated hydrocarbon used as a fungicide. In addition, the compound is used as an insecticide for agricultural purposes and other in-house treatments [41]. Furthermore, the compound is incorporated in the manufacture of certain commodities such as insulators, ropes, paints, and adhesives. It is synthesized either by alkaline hydrolysis or direct chlorination of chlorobenzenes and phenols, respectively [42]. In addition to the tens of thousands of tons used for different purposes, metabolism of other organochlorine compounds such as lindane was shown to be metabolized to produce pentachlorophenol [43-45] - a persistent organochlorine compound with a half-life of 6-7 months, which makes it able to contaminate various environmental bodies such as soil and water [46]. There are many reports of PCP contamination in soil, wood treatment sites, underground water, and deserted factories [47]. The international agency for research on cancer (IARC) has classified pentachlorophenol as a possible human carcinogen. One of the major toxic metabolites of pentachlorophenol is tetrachlorohydroquinone [48].

Cytosolic glutathione S-transferase with significant sequence similarity to maleylacetoacetate isomerase (a zeta class GST) was found to play a key role in the biodegradation of pentachlorophenol. This enzyme, designated as tetrachlorohydroquinone (TCHQ) dehalogenase, was first identified from Sphingobium chlorophenolicum [40]. The TCHQ dehalogenase from Sphingobium chlorophenolicum is the most extensively studied dehalogenase in bacterial GSTs. The enzyme catalyzes the two-step reductive dechlorination process to converttetrachlorohydroquinone to dichlorohydroquinone (Fig. 2) [38]. Surprisingly, unlike the other GST superfamily that requires one molecule of GSH, the TCHQ dehalogenase requires the equivalent of two molecules of GSH at each

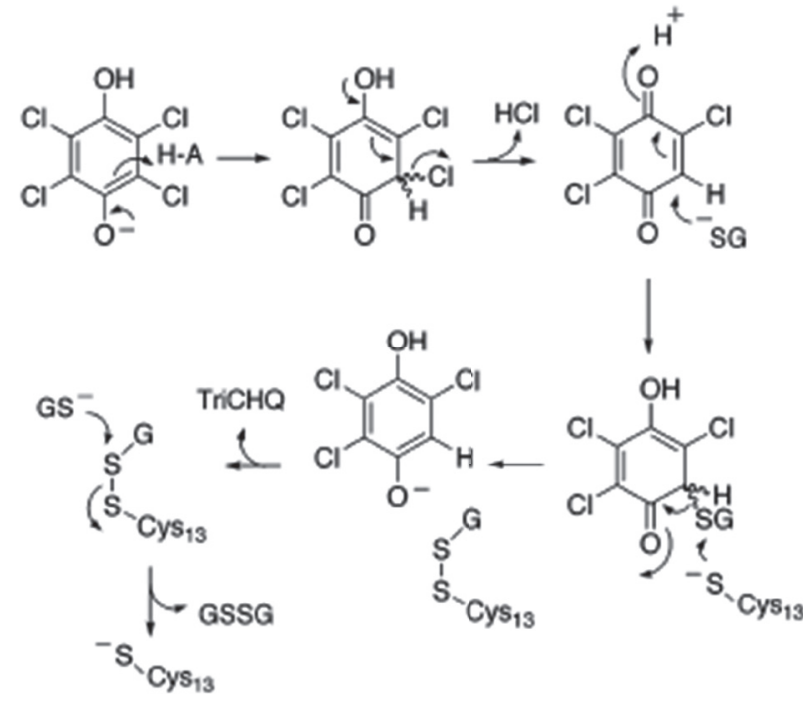

Fig. 2. Postulated mechanism of dehalogenation of tetrachlorohydroquinone (TCHQ) by TCHQ dehalogenase from Sphingobium chlorophenolicum.

stage of the reductive dehalogenation. Furthermore, the GSH molecules are not regenerated at the end of the reaction but are oxidized to glutathione disulfide [38]. The initial reaction in the biodegradation of pentachlorophenol involves hydroxylase, which produces tetrachlorobenzoquinone. Tetrachlorobenzoquinone is converted into tetrachlorohydroquinone by the action of a reductase [49]. The next two successive reactions involve reductive dehalogenation by the TCHQ dehalogenase to generate dichlorohydroquinone. In the proposed mechanism of the reaction, the first GSH molecule is used in the nucleophilic attack on the substrate while the second GSH molecule is used in the thiol-disulfide exchange reaction to form oxidized glutathione (GSSG). Cysteine13 was found to play a key role in the second part of the reaction, whereby its attack on the glutathionyl results in the release of the reduced substrate. The final step of the reaction involves the regeneration of the active site, cysteine, and the formation of glutathione disulfide. Even though the binding of the second glutathione in thiol-disulfide exchange reaction was found to be very weak, the enzyme was found to catalyze the reaction at rate 10000 -fold more than other typical thiol-disulfide exchange reactions $[38,40,50]$.

\section{Dehalogenation of 2,5-dichlorohydroquinone}

2,5-dichlorohydroquinone is a metabolite generated during the biodegradation of gammahexachlorocyclohexane, also known as lindane $[43,51]$. Lindane is one of the notorious and highly halogenated insecticides used worldwide for the control of agricultural and public health pests. Although most countries have prohibited and banned the use of lindane because of its persistence and toxicity, for economic reasons the compound is still being produced 

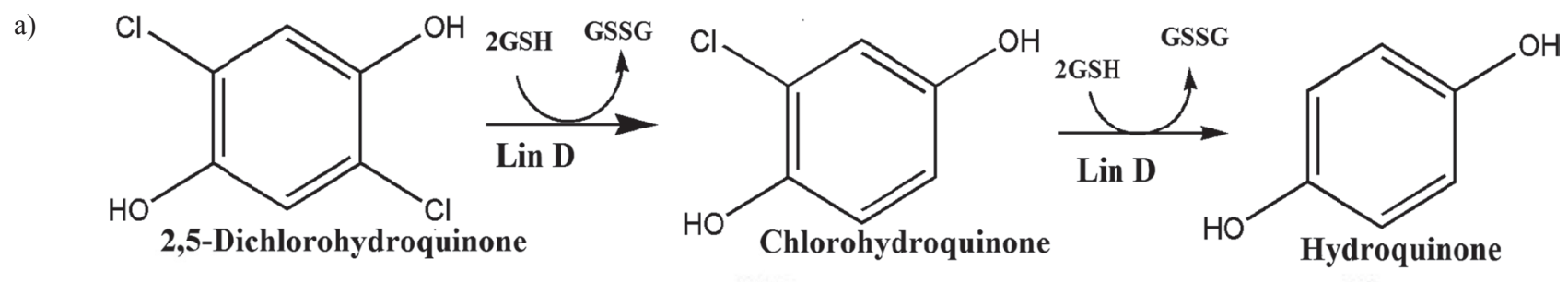<smiles>CCNc1nc(Cl)nc(NC(C)C)n1</smiles>

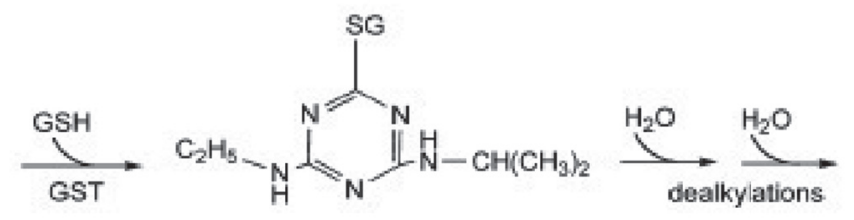<smiles>O=S(=O)([O-])c1nc(O)nc(O)n1</smiles>

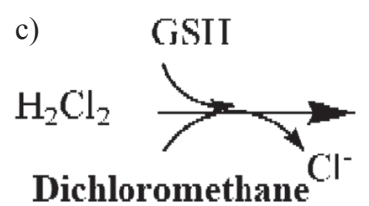

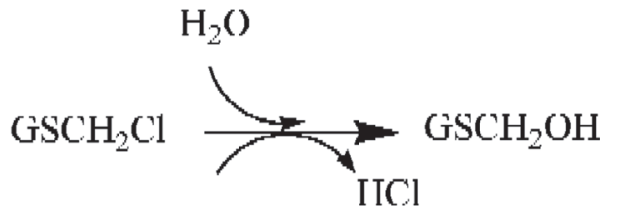

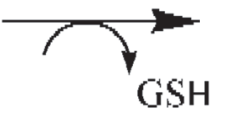

\section{$\mathrm{HCOH}$}

Formaldehyde

Fig. 3. Reductive dehalogenation of 2,5-dichlorohydroquinone to quinone by Lin D (a zeta class glutathione S-transferase) from Sphigomonas paucimobilis UT26 b Conversion of atrazine to cyanuric acid by Pseudomonas strain ADP, GST catalyzes the first dehalogenation step before the two subsequent dealkylations that produces cyanuric acid c) Biodegradation of dichloromethane to formaldehyde by two different strains of bacteria (Methylobacterium dichloromethanicum (DM4) and Methylophilus leisingeri (DM 11).

and used in some countries [47, 52]. This makes it available to contaminate new sites in addition to the previously contaminated sites. Various reports of contamination by lindane in both land and water bodies were reported [52]. The compound exerts various toxicities ranging from reproductive to renal toxicities [53-54].

The most well-studied biodegradation of lindane is by the bacteria Sphigomonas paucimobilis UT26 $[51,55]$. The organism contained a series of enzymes designated as Lin A, Lin B, Lin C, Lin D, and Lin E, which sequentially degrade lindane to hydroquinone. Lin $\mathrm{D}$, in particular, was found to be a zeta class glutathionedependent reductive dehalogenase through sequence alignment studies and biochemical characterization [56]. The enzyme partakes in the biodegradation of lindane by dehalogenation of 2,5-dichlorohydroquinone (a byproduct of Lin C) to produce hydroquinone via chlorohydroquinone. The hydroquinone is subsequently converted into carbon dioxide and energy is produced in the process. The proposed mechanism of the reaction was similar to the one found in TCHQ dehalogenase. Lin $\mathrm{D}$ utilizes two molecules of reduced glutathione (GSH) in each of the two stages of the reaction to produce hydroquinone (Fig. 3a) [57].

\section{Dehalogenation of Herbicides}

Atrazine is a synthetic and one of the most widely used herbicides after glyphosate for effectively controlling grassy weeds [58]. Its mechanism of action involves disrupting the photosystem II by selective binding to a plant's specific plastoquinone-binding protein. This causes a disruption in the electron transport system of the plant and its eventual death [59]. However, the compound is relatively persistent in soil, lasting for up to 4 years in some types of soils and therefore migrating from soil to underground water, which causes its contamination $[58,60]$. Despite atrazine having been banned since 2004 in European countries, as of 2014 it is the second mostused pesticide in the United States and the most widely used in Australia [58]. It is considered one of the major water contaminants in the United States [61]. It is an endocrine disruptor causing hormonal imbalance. There is also increasing concern about the effect of atrazine on intrauterine growth and preterm delivery [62].

Cytosolic glutathione S-transferases from several bacterial species have been shown to play a role in the biodegradation of atrazine. Biodegradation of atrazine is carried out by a single microorganism or microbial consortium [63-64]. The best-studied response of microbial population on exposure to atrazine is derived from Pseudomonas strain ADP [64]. This strain responded by producing enzymes that degrade the atrazine to cyanuric acid [65-66]. The first step involves the removal of chlorine atom through conjugation with GSH catalyzed by glutathione S-transferase. This is subsequently followed by an additional three enzymatic steps that degrade the compound to cyanuric acid [67]. A glutathione S-transferase from Pseudomonas strain ADP catalyzes the initial dehalogenation reaction (Fig. 3b), and this produces the substrate for the next enzymatic steps [64]. Two subsequent dealkylation steps produce cyanuric acid, which then further metabolize to carbon dioxide and ammonia by Pseudomonas sp. ADP and many other soil bacteria [5, 68]. In another 
study using soil bacterium Ochrobactrum antrophi that solely utilized atrazine as its carbon source, there was an increase in the level of a specific beta class GST from the organism, suggesting a vital role played by this GST in the biodegradation process [69]. Furthermore, a recombinant cell extract encoding a BphK glutathione S-transferase from Burkholderia xenovorans LB400 was also found to display dehalogenation function against atrazine [70]. The BphK from Burkholderia xenovorans LB 400 was also found to display the dehalogenation function against Clean-Up, a herbicide containing $60 \%$ atrazine and $40 \%$ aminotriazole used to prevent weed recurrence.

Another herbicide known to be a substrate for GST is 2,4-dichlorophenoxyacetic acid, an organochlorine herbicide widely used in various type of crops to control broadleaf weeds. The relative persistence of the herbicide makes it one of the more widely detected water contaminants affecting both humans and aquatic animals [71]. Furthermore, the herbicide has the tendency to bioaccumulate in plants and aquatic animals, and therefore ingestion of such plants or animals can result in various health complications. The world health organization has classified 2,4-dichlorophenoxyacetic acid as a moderately hazardous substance [72]. The compound was also classified as a possible carcinogenic substance by the international agency for research on cancer [73]. A specific beta class glutathione S-transferase (BphK) from Burkholderia xenovorans LB400 that was found to function in the dehalogenation of toxic metabolites generated during polychlorobiphenyls degradation was also found to exhibit dechlorination function against 2,4-dichlorophenoxy acetic acid [70]. This GST was also found to exhibit dechlorination function against another herbicide, Pentanochlor. Pentanochlor is an aniline selective herbicide used to control weeds in various plants. The herbicide was classified as toxic to plants, animals, and aquatic organisms by the United States Environmental Protection Agency. The dehalogenation is thought to help reduce the recalcitrance of these compounds, thereby making them vulnerable to biodegradation. In addition, it also makes the carbon skeleton of atrazine available to other biodegradative organisms, thereby enhancing and speeding up the biodegradation process. A laboratory phytoprotection experiment also showed that dechlorination of organochlorine herbicides contributed greatly to providing a cleaner environment, offered a protective effect for plants, and enhanced plant growth [70].

\section{Dehalogenation of Dichloromethane}

Dichloromethane is an organic solvent used extensively in industries as a solvent and a cleaner. It is a common water contaminant and a volatile compound whose exposure to humans and other animals causes various types of toxicity [74]. Dichloromethane is used in many products such as paints, adhesives, and spray shoe polishes, and this makes it available in the air around environments and therefore prone to exposure by humans and other animals, and subsequent toxicity [75]. It was considered a likely carcinogenic agent based on animal studies [76-77]. Dichloromethane was also found to cause neurological disorders characterized by impaired memory and decreased motor activity in mice [76].

DCM dehalogenases in bacteria belong to the GST superfamily and they are classified as theta class GST because of their close relationship to the eukaryotic theta GSTs [5]. Two DCM dehalogenases isolated from Methylobacterium dichloromethanicum (DM4) and Methylophilus leisingeri (DM 11) with 56\% sequence identity are among the most extensively studied and characterized GSTs $[25,78]$. They both have the same essential serine residue at the $\mathrm{N}$-terminal sequence, which plays a role in the catalytic activity of the protein [5]. The difference between the two dehalogenases lies in the fact that DM11 has a greater rate of dechlorination than DM4 when grown in the same millimolar concentration of DCM. However, these are the properties expected considering the origin of the two DCMDs: DCM11 was isolated from a sample that was exposed to high level of DCM for long period, while DM4 was isolated from a site with a presumably low concentration of DCM [25, 79]. DCM dehalogenase catalyzes a reaction in which the GSH attack DCM to form unstable thioester linkage, which decomposes spontaneously to form formaldehyde and regenerate GSH (Fig. 3c) [80].

\section{Dehalogenation of Dichloroacetate}

Dichloroacetate is a metabolite generated by various industrial solvents and also a by-product of water chlorination. The compound has been investigated as being responsible for various health-related implications such as hepatoxicity, neoplasia, and even cancer [81]. In aquatic organisms, DCA was found to induce the formation of reactive oxygen species and other various forms of toxicities [81]. However, other various therapeutic potentials of the compound in the treatment of lactic acidosis and even for cancer treatments were also investigated [81]. Among the cytosolic GSTs, only zeta-class GSTs from humans, rats, and mice were investigated for dichloroacetate dechlorinating activity. In addition, other alpha halo acids were also found to be substrates for these zeta class GSTs [82-83]. Despite the fact that zeta class GSTs are widely distributed in mammals, plants, fungi, and bacteria, the reports of dichloroacetate dechlorinating activity of this class of GST was only investigated thoroughly in mammalian species. In bacteria, a newly discovered Rho class GST from Synechocystis PCC 6803 was found to have a dichloroacetate dechlorinating activity against DCA in a similar manner to zeta class GST [7]. The proposed mechanism of the reaction involves glutathione-catalyzed dehalogenation of DCA to form glyoxylate. The glyoxylate can then be converted into either glycolate, oxalate, or some other non-essential amino acids (Fig. 4). 

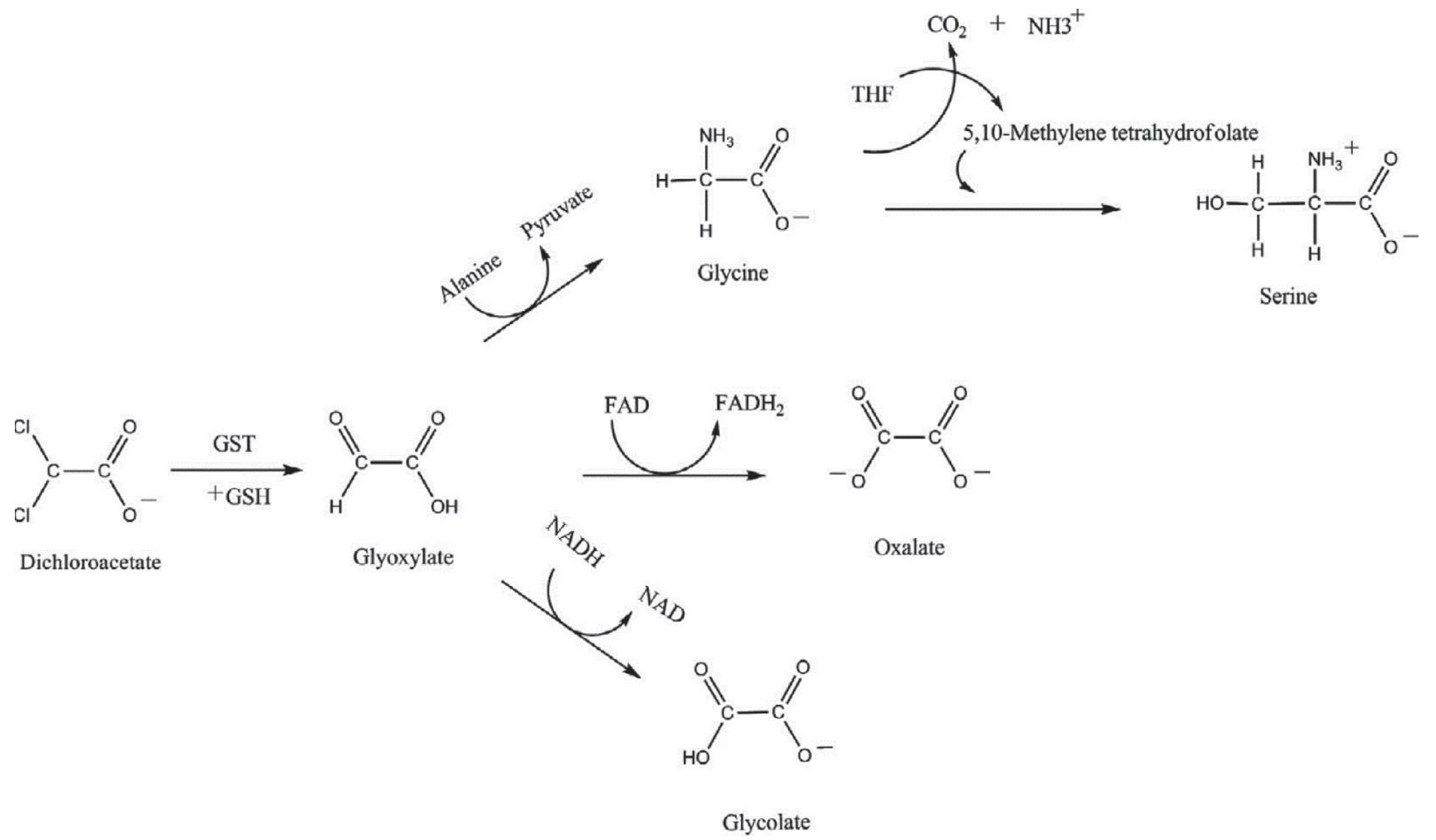

Fig. 4. Dehalogenation of dichloroacetate (DCA) by rho class glutathione S-transferase from Synechocystis sp. PCC6803 and metabolic degradative pathway of glyoxylate.

\section{Dehalogenation of Metabolites of PCB Biodegradation}

Polychlorinated biphenyls (PCBs) are synthetic organic chemicals that contain several chlorine atoms attached to the biphenyl carbon skeleton [84]. PCBs contain several different isomers known as congeners, and it has been estimated that about 20-60 different congeners are present in commercial formulations [85]. Several million tons of PCBs were estimated to have been produced worldwide, with a significant amount finding itself deposited into the environment and causing a great threat to human health and animals [86]. They have a high degree of hydrophobicity and versatility in composition, as well as chemical stability, and these make it difficult for PCBs to undergo natural degradation, and they remain deposited for decades in the environment [87]. Furthermore, the volatility and long range of transport of PCBs ensures their distribution into almost all sorts of environments irrespective of whether it has ever been produced or used in that environment [88]. Although PCBs were previously considered probable carcinogens, some studies recently have classified one of the congeners as a carcinogen, which has prompted a complete re-evaluation of PCBs [89]. A meta-analysis performed on Yucheng and Yusho populations in Taiwan and Japan exposed to polychlorinated biphenyls and dibenzofurans over 40 years ago showed a significant elevation in many types of cancers, heart diseases, and hepatic disease mortalities exposed in men [90]. Furthermore, elevated mortality as a result of liver cancer in women was also identified [90]. Other studies have also implicated higher chlorinated congeners to be efficacious promoters of cancer, while the lower chlorinated congeners are potential initiators [89]. Exposure to high concentrations of PCBs was also found to cause acute toxicity and other health implications ranging from impaired immune function, weight loss, hepatitis, depression, dizziness, behavioral alteration, and thyroid gland injuries [91]. PCBs are among the twelve chemicals classified in the Stockholm convention to be prioritized for eventual elimination by 2025 [92].

One of the shortcomings encountered by polychlorobiphenyl-degrading organisms is the presence of dead-end metabolites, which are detrimental to the organisms themselves [93]. These metabolites include chlorobenzoates, dihydrodiols, dihydroxybiphenyls, 3-chloro-2-hydroxy-6-oxo-6-phenyl-2,4-dienoate (HOPDA), and many others. In particular, the transformation of chlorobenzoate results in the formation of the downstream toxic product protoanemonin (an antibiotic that kills the PCB degraders). The formation of protoanemonin was thought to be responsible for poor performance and survival of PCB degraders in soil microcosm studies [93]. Biodegradation of DDT by Alcaligenes eutrophus A5 was also shown to result in the release of 4-chlorobenzoate as a dead-end metabolite [94]. Other metabolites such as Dihydroxybiphenyls inhibit bacterial cell separation by affecting the DNA content of the bacteria [95]. Chlorosubstituted HOPDAs on dienoate were found 
1.

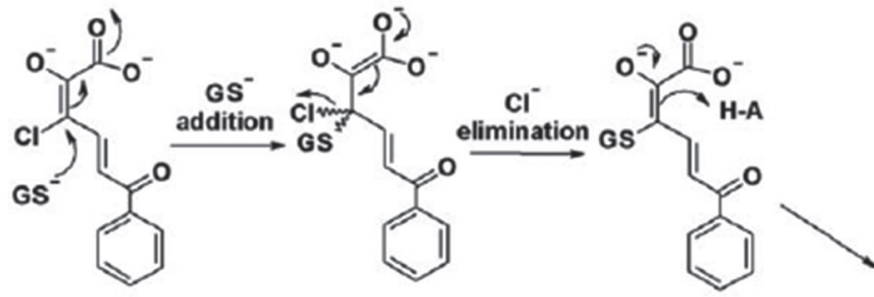

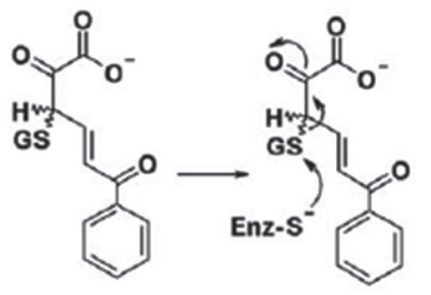

2.
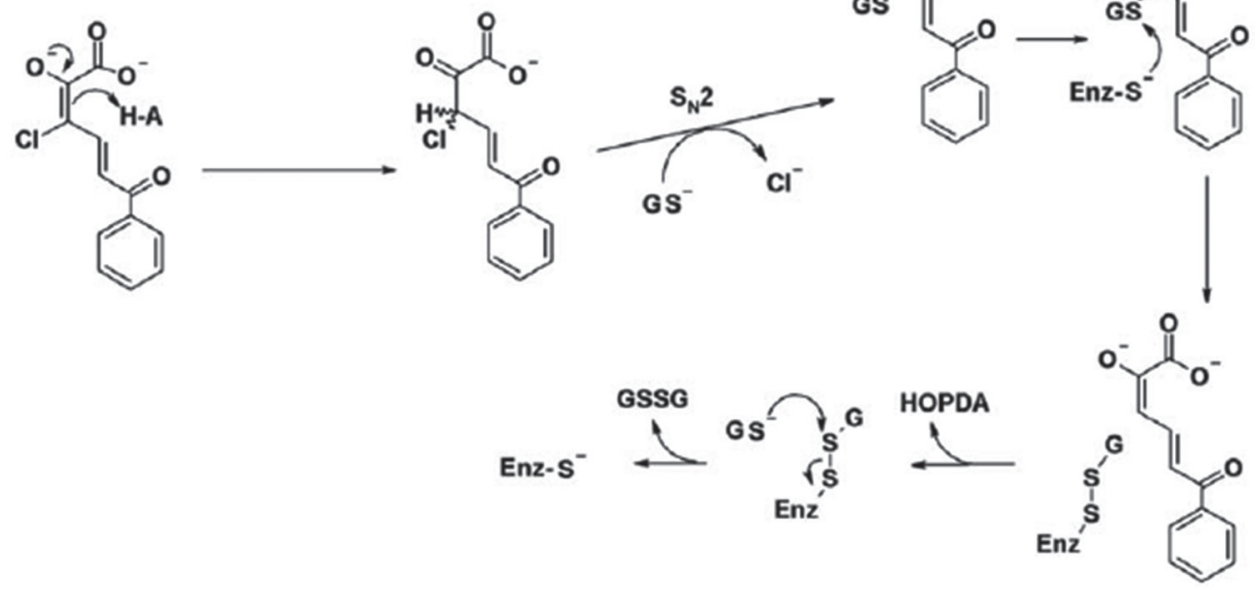

Fig. 5. Proposed mechanism for the dehalogenation of 3-chloro HOPDA by the BphK from Burkholderia xenovorans LB400. The first mechanism depicts the simple addition followed by elimination step. The second mechanism depicts the S2N-mediated mechanism.

to competitively inhibit 2-Hydroxy-6-phenyl-6-oxohexa-2,4-dienoate (HOPDA) hydrolase, an enzyme in the fourth step of PCB biodegradation [39].

A beta class cytosolic glutathione $\mathrm{S}$-transferase termed BphK was found to be situated within the $b p h$ operon responsible for polychlorobiphenyl degradation in some organisms such as Burkholderia xenovorans LB400. The enzyme was found to be responsible for dehalogenation of toxic metabolites such as chlorobenzoates, 4-chloro2-hydroxy-6-oxo-6-phenyl-2,4-dienoate(HOPDA), and 3-chloro-2-hydroxy-6-oxo-6-phenyl-2,4-dienoate (HOPDA) generated during the biodegradation process [39]. The existence of BphK in some biphenyl degraders was attributed to the high degradation capability of PCBs in some biphenyl/PCB degraders such as Burkholderia xenovorans LB400, considered a model organism for PCB biodegradation [96]. The mechanism of the dehalogenation reaction was proposed to be similar to the one found in tetrachlorohydroquinone [39]. Two mechanisms were proposed for the dehalogenation of HOPDAs by the BphK LB400. The first mechanism was proposed to be mediated by the simple addition of activated GS-, followed by the elimination of the chloride ion. The second mechanism was proposed to be mediated through the nucleophilic substitution bimolecular mechanism $\left(\mathrm{S}_{2} \mathrm{~N}\right)$ (Fig. 5). This involves displacement of the chloride ion at positions 3 and 5 of the 3-and 5-chloro HOPDAs, respectively, by the attack from GSthe regeneration of GSH was proposed to be mediated by the second GSH in a manner analogous to that proposed for TCHQ dehalogenase [39].

\section{Summary and Conclusion}

Recent decades have seen a growing interest in economically feasible strategies to deal with the growing number of organohalide pollutants. Recent studies have shown the existence of several novel classes of cytosolic glutathione S-transferases in bacteria with a potential for a wide range of biotechnological applications to reduce the toxicity of various organochlorine pollutants. The wide-ranging repertoire of substrates recognized by cGST makes them well suited for biotechnological application in bioremediation. However, the utilization of bacterial cytosolic GSTs in the degradation and detoxification have seldom been applied for large-scale bioremediation processes. Most of the studies on cGST in bacteria are still at an infant stage. Knowledge of the stability of the enzymes in relation to the environmental condition is worth determining in order to translate the much-needed technology into reality. In addition, random mutagenesis will yield insight into the generation of enzymes with altered substrate specificity and catalytic efficiency that can be targeted against a particular pollutant. Study of the stability of the mutants is also worth determining as this will determine how effective the altered enzyme can be employed for a particular purpose. Therefore, there are important financial and ecological reasons for better understanding of cGST in bacteria and their implementation in bioremediation processes. 


\section{Acknowledgements}

This work was supported by the University of Malaya IPPP (grant No. PG170-2016A).

\section{Conflict of Interest}

The authors declare no conflict of interest.

\section{References}

1. SIMARANI K., YUSOFF W.H.A.C., ALIAS Z. Purification of Glutathione Transferases (GSTs) from Identified Rhizospheric Bacteria. Sains Malays 45 (3), 1057, 2016.

2. LONGKUMER T., PARTHASARATHY S., VEMURI S.G., SIDDAVATTAM D. OxyR-dependent expression of a novel glutathione S-transferase (Abgst01) gene in Acinetobacter baumannii DS002 and its role in biotransformation of organophosphate insecticides. Microbiology+ 160 (1), 102, 2014.

3. PLANCARTE A., ROMERO J., NAVA G., REYES H., HERNÁNDEZ, M. Evaluation of the non-catalytic binding function of Ts26GST a glutathione transferase isoform of Taenia solium. Exp. Parasitol 138 (3), 63, 2014.

4. MUNYAMPUNDU J-P., XU Y-P., CAI X-Z. Phi class of glutathione S-transferase gene superfamily widely exists in nonplant taxonomic groups. Evol. Bioinform. 12 (4), 59, 2016.

5. ALLOCATI N., FEDERICI L., MASULLI M., DI ILIO C. Glutathione transferases in bacteria. Febs J. 276 (2), 75, 2009.

6. GALL D.L., KIM H.L.U. F., DONOHUE T.J., NOGUERA D.R., RALPH J. Stereochemical features of glutathionedependent enzymes in the Sphingobium sp. strain SYK$6 \beta$-aryl etherase pathway. J. Biol. Chem. 289 (12), 8656, 2014.

7. PANDEY T., CHHETRI G., CHINTA R., KUMAR B., SINGH D.B., TRIPATHI T. Functional classification and biochemical characterization of a novel rho class glutathione S-transferase in Synechocystis PCC 6803. Febs Open Bio. 5 (1), 1, 2015.

8. SKOPELITOU K., DHAVALA P., PAPAGEORGIOU A.C., LABROU N.E. A glutathione transferase from Agrobacterium tumefaciens reveals a novel class of bacterial GST superfamily. PloS One 7 (4), 34263, 2012.

9. STOURMAN N.V., BRANCH M.C., SCHAAB M.R., HARP J.M., LADNER J.E., ARMSTRONG R.N. Structure and function of YghU, a nu-class glutathione transferase related to YfcG from Escherichia coli. Biochem. 50 (7), 1274, 2011.

10. LIU L-Y., MA W-L., JIA H-L., ZHANG Z-F., SONG W-W., LI, Y-F. Research on persistent organic pollutants in China on a national scale: 10 years after the enforcement of the Stockholm Convention. Environ. Pollut. 217 (3), 70, 2016.

11. ULFIK A., NOWAK S. Determinants of Municipal Waste Management in Sustainable Development of Regions in Poland. Polish J. Environ. Studies, 23, 3, 2014.

12. JUGDER B.-E., ERTAN H., LEE M., MANEFIELD M., MARQUIS C.P. Reductive dehalogenases come of age in biological destruction of organohalides. Trends Biotechnol. 33 (4), 595, 2015.
13. LARKIN M.A., BLACKSHIELDS G., BROWN N., CHENNA R., MCGETTIGAN P.A., MCWILLIAM H. Clustal W and Clustal X version 2.0. Bioinformatics 23 (21), 2947, 2007.

14. SAITOU N., NEI M. The neighbor-joining method: a new method for reconstructing phylogenetic trees. Mol. Biol. Evol. 4 (4), 406, 1987

15. ZUCKERKANDL E., PAULING L. Evolutionary divergence and convergence in proteins. Evolving genes and proteins 97 (3), 97, 1965

16. TAMURA K., STECHER G., PETERSON D., FILIPSKI A., KUMAR S. MEGA6: molecular evolutionary genetics analysis version 6.0. Mol. Biol. Evol. 30 (12), 2725, 2013.

17. MASHIYAMA S.T., MALABANAN M.M., AKIVA E., BHOSLE R., BRANCH M.C., HILLERICH B. Largescale determination of sequence, structure, and function relationships in cytosolic glutathione transferases across the biosphere. PLoS Biol. 12 (4), 843, 2014.

18. ALLOCATI N., FEDERICI L., MASULLI M., DI ILIO C. Distribution of glutathione transferases in Gram-positive bacteria and Archaea. Biochimie 94 (3), 588, 2012.

19. SHEHU D., ALIAS Z. Functional Role of Tyr12 in the catalytic activity of Novel Zeta Like Glutathione S-Transferase from Acidovorax sp. KKS102. The protein journal 37 (3), 261, 2018.

20. OAKLEY A.J. Glutathione transferases: new functions. Curr. Opin. Struct. Biol. 15 (6),716, 2005.

21. BRENNAN E., MCGUINNESS M., DOWLING D.N. Bioinformatic analysis and in vitro site-directed mutagenesis of conserved amino acids in BphK LB400, a specific bacterial glutathione transferase. Int. Biodeter. Biodegra. 63, 928, 2009.

22. DEPONTE M. Glutathione catalysis and the reaction mechanisms of glutathione-dependent enzymes, Biochim. Biophys. Acta. 1830, 3217, 2013.

23. ROSSJOHN J., POLEKHINA G., FEIL S.C., ALLOCATI N., MASULLI M., DI ILIO C., PARKER M.W. A mixed disulfide bond in bacterial glutathione transferase: functional and evolutionary implications. Structure. 6, 721, 1998.

24. N. ALlOCATI E., CASALONE M., MASUlLi G., POLEKHINA J., ROSSJOHN M.W., PARKER D. Carmine, Evaluation of the role of two conserved activesite residues in Beta class glutathione S-transferases. Biochem. J. 351, 341, 2000.

25. SCHOLTZ R., WACKETT L.P., EGLI C., COOK A.M., LEISINGER T. Dichloromethane dehalogenase with improved catalytic activity isolated from a fast-growing dichloromethane-utilizing bacterium. J. Bacteriol. 170 (12), 5698,1988

26. FIRSOVA Y.E., FEDOROV D., TROTSENKO Y.A. Analysis of the 3 '-region of the dcmA gene of dichloromethane dehalogenase of Methylobacterium dichloromethanicum DM4. Microbiology+. 80 (6), 805, 2011.

27. MULLER E.E., BRINGEL F., VUILLEUMIER S. Dichloromethane-degrading bacteria in the genomic age. Res. Microbiol. 162 (9), 869, 2011.

28. YU J., LIU Q., LIU L., CHEN J. Cloning and characterization of dichloromethane dehalogenase from Methylobacterium rhodesianum for dichloromethane degradation. Bioremediat. J. 21 (2), 71, 2017.

29. BOARD G.P., BAKER T.R., CHELVANAYAGAM G., JERMIIN S.L. Zeta, a novel class of glutathione 
transferases in a range of species from plants to humans. Biochem. J. 328 (3), 929, 1997.

30. OZTETIK E., KOCKAR F., ALPER M., ISCAN M. Molecular characterization of zeta class glutathione S-transferases from Pinus brutia Ten. J. Genet. 94 (3), 417, 2015.

31. JAMES M.O., JAHN S.C., ZHONG G., SMELTZ M.G., HU Z., STACPOOLE P.W. Therapeutic applications of dichloroacetate and the role of glutathione transferase zeta1. Pharmacol. Therapeut. 170 (4), 166, 2017.

32. YAMAMOTO K., SHIGEOKA Y., ASO Y., BANNO Y., KIMURA M., NAKASHIMA T. Molecular and biochemical characterization of a Zeta-class glutathione S-transferase of the Silkmoth. Pestic. Biochem. Physiol. 94 (1), 30, 2009

33. HABASH M., CHU B.C., TREVORS J.T., LEE H. Mutational study of the role of N-terminal amino acid residues in tetrachlorohydroquinone reductive dehalogenase from Sphingomonas sp. UG30. Res. Microbiol. 160 (8), 553, 2009.

34. MARSH M., SHOEMARK D.K., JACOB A., ROBINSON C., CAHILL B., ZHOU N-Y. Structure of bacterial glutathione-S-transferase maleyl pyruvate isomerase and implications for mechanism of isomerisation. J. Mol. Biol. 384 (1), 165, 2008

35. FANG T., LI D-F., ZHOU N-Y. Identification and clarification of the role of key active site residues in bacterial glutathione S-transferase zeta/maleylpyruvate isomerase. Biochem. Bioph. Res. Co. 410 (3), 452, 2011.

36. WIKTELIUS E., STENBERG G. Novel class of glutathione transferases from cyanobacteria exhibit high catalytic activities towards naturally occurring isothiocyanates. Biochem. J. 406 (1), 115, 2007.

37. WADINGTON M.C., LADNER J.E., STOURMAN N.V., HARP J.M., ARMSTRONG R.N. Analysis of the structure and function of $\mathrm{YfcG}$ from Escherichia coli reveals an efficient and unique disulfide bond reductase. Biochemistry-US 48 (28), 6559, 2009.

38. WARNER J.R., LAWSON S.L., COPLEY S.D. A Mechanistic Investigation of the Thiol- Disulfide Exchange Step in the Reductive Dehalogenation Catalyzed by Tetrachlorohydroquinone Dehalogenase. BiochemistryUS. 44 (30), 10360, 2005.

39. FORTIN P.D., HORSMAN G.P., YANG H.M., ELTIS L.D. A glutathione S-transferase catalyzes the dehalogenation of inhibitory metabolites of polychlorinated biphenyls, Journal of bacteriology, 188, 4424, 2006.

40. COPLEY S.D., ROKICKI J., TURNER P., DALIGAULT H., NOLAN M., LAND M. The whole genome sequence of Sphingobium chlorophenolicum L-1: insights into the evolution of the pentachlorophenol degradation pathway. Genome Biol. Evol. 4 (2), 184, 2011.

41. CAO M., WANG L., AI Z., ZHANG L. Efficient remediation of pentachlorophenol contaminated soil with tetrapolyphosphate washing and subsequent ZVI/Air treatment. J. Hazard. Mater. 292, 27, 2015.

42. YU J., SAVAGE P.E. Reaction pathways in pentachlorophenol synthesis. 1. Temperature-programmed reaction. Ind. Eng. Chem research. 43, 5021, 2004.

43. LAL R., PANDEY G., SHARMA P., KUMARI K., MALHOTRA S., PANDEY R. Biochemistry of microbial degradation of hexachlorocyclohexane and prospects for bioremediation. MicrobioL. Mol. Biol. Rev. 74 (1), 58, 2010.

44. SALAM J.A., DAS N. Remediation of lindane from environment-an overview. Int. J. Adv. Biol. Res. 2 (9), 15, 2012.
45. LOPEZ-ECHARTEA E., MACEK T., DEMNEROVA K., UHLIK O. Bacterial Biotransformation of Pentachlorophenol and Micropollutants Formed during Its Production Process. Int. J. Env. Res. Pub. He. 13 (11), 1146, 2016.

46. SMARANDA C., BULGARIU L., ROSCA M., TURCULET R., GHINEA C., GAVRILESCU M. Evaluation of pentachlorophenol leaching potential in natural soils IEEE. 1, 4, 2015.

47. MALISZEWSKA-KORDYBACH B., SMRECZAK B., KLIMKOWICZ-PAWLAS A. Evaluation of the Status of Contamination of Arable Soils in Poland with DDT and HCH Residues; National and Regional Scales. Polish J. Env. Stud. 23, 1, 2014.

48. PIETSCH C., HOLLENDER J., DORUSCH, F., BURKHARDT-HOLM P. Cytotoxic effects of pentachlorophenol (PCP) and its metabolite tetrachlorohydroquinone (TCHQ) on liver cells are modulated by antioxidants. Cell Biol. Toxicol. 30, 233, 2014.

49. DAMS R., PATON G., KILLHAM K. Rhizoremediation of pentachlorophenol by Sphingobium chlorophenolicum ATCC 39723. Chemosphere. 68, 864, 2007.

50. BOSSO L., CRISTINZIO G. A comprehensive overview of bacteria and fungi used for pentachlorophenol biodegradation. Rev. Env. Sc. Biotech. 13 (4), 387, 2014.

51. CAMACHO-PÉREZ B., RÍOS-LEAL E., RINDERKNECHT-SEIJAS N., POGGI-VARALDO H.M. Enzymes involved in the biodegradation of hexachlorocyclohexane: a mini review. J. Env. Manage. 95 (2), 306, 2012.

52. FUSCOLETTI V., ACHENE L., GISMONDI, F., LAMARRA D., LUCENTINI L., SPINA S., VESCHETTI E., TURRIO-BALDASSARRI L. Presence of epsilon HCH together with four other $\mathrm{HCH}$ isomers in drinking water, groundwater and soil in a former Lindane production site. B. Environ. Contam. Tox. 95, 108, 2015.

53. MEHTA P. Toxic Effect of Lindane on Male Reproductive Cells in Mammals. Int. J. Curr. Microbiol. App. Sci. 5 (3), 76, 2016.

54. PRASAD W.V., SRILATHA C., SAILAJA N., RAJU N., JAYASREE N. Amelioration of Gammahexachlorocyclohexane (Lindane) induced renal toxicity by Camellia sinensis in Wistar rats. Vet. world 9 (11), 1331 2016.

55. NAGATA Y., FUTAMURA A., MIYAUCHI K., TAKAGI M. Two Different Types of Dehalogenases, LinA and LinB, Involved in $\gamma$-Hexachlorocyclohexane Degradation in Sphingomonas paucimobilis UT26 Are Localized in the Periplasmic Space without Molecular Processing. J. Bacteriol. 81 (17), 5409, 1999.

56. SANGWAN N., LATA P., DWIVEDI V., SINGH A., NIHARIKA N., KAUR J. Comparative metagenomic analysis of soil microbial communities across three hexachlorocyclohexane contamination levels. PLoS One 7 (9), 462, 2012.

57. NAGATA Y., ENDO R., ITO M., OHTSUBO Y., TSUDA, M. Aerobic degradation of lindane ( $\gamma$-hexachlorocyclohexane) in bacteria and its biochemical and molecular basis. Appl. Microbiol. Biot. 76, 741, 2007.

58. HEAP I. Herbicide resistant weeds. Integrated pest management: Springer: USA, 281, 2014.

59. JABLONOWSKI N.D., SCHÄFFER A., BURAUEL P. Still present after all these years: persistence plus potential toxicity raise questions about the use of atrazine. Environ. Sci. Pollut. Res. 18 (2), 328, 2011. 
60. KHAN A., SHAH N., KHAN M.S., AHMAD M.S., FAROOQ M., ADNAN M. Quantitative Determination of Lethal Concentration Lc 50 of Atrazine on Biochemical Parameters; Total Protein and Serum Albumin of Freshwater Fish Grass Carp (Ctenopharyngodon idella). Pol. J. Environ. Stud. 25 (4), 1555, 2016.

61. GLASSMEYER S.T., FURLONG E.T., KOLPIN D.W., BATT A.L., BENSON R., BOONE J.S. Nationwide reconnaissance of contaminants of emerging concern in source and treated drinking waters of the United States. Sci. Total Environ. 581 (6), 909, 2017.

62. STAYNER L.T., ALMBERG K., JONES R., GRABER J., PEDERSEN M., TURYK M. Atrazine and nitrate in drinking water and the risk of preterm delivery and low birth weight in four Midwestern states. Environ. Res. 152, 294, 2017.

63. SMITH D., ALVEY S., CROWLEY D.E. Cooperative catabolic pathways within an atrazine-degrading enrichment culture isolated from soil. Fems Microbiol. Ecol. 53 (2), 265, 2005.

64. DEVERS-LAMRANI M., SPOR A., MOUNIER A., MARTIN-LAURENT F. Draft genome sequence of Pseudomonas sp. strain ADP, a bacterial model for studying the degradation of the herbicide atrazine. Genome announcements 4 (1), 1733, 2016.

65. NOOR S., CHANGEY F., OAKESHOTT J.G., SCOTT C., MARTIN-LAURENT F. Ongoing functional evolution of the bacterial atrazine chlorohydrolase AtzA. Biodegradation 25 (1), 21, 2014.

66. STELTING S.A., BURNS R.G., SUNNA A., BUNT C.R. Survival in sterile soil and atrazine degradation of Pseudomonas sp. strain ADP immobilized on zeolite. Bioremediat. J. 18 (4), 309, 2014.

67. BOOPATHY R. Anaerobic degradation of atrazine. Int. Biodeter. Biodegr. 119 (8), 626, 2017.

68. DE SOUZA M., WACKETT L.P., BOUNDY-MILLS K.L., MANDELBAUM R.T., SADOWSKY M.J. Cloning, characterization, and expression of a gene region from Pseudomonas sp. strain ADP involved in the dechlorination of atrazine. Appl. Environ. Microbiol. 61, 3373, 1995.

69. KOLIĆ N.U., HRŠAK D., KOLAR A.B., PETRIĆ I., STIPIČEVIC S., SOULAS G., MARTIN-LAURENTF. Combined metabolic activity within an atrazinemineralizing community enriched from agrochemical factory soil. Int. Biodeter. Biodegr. 60, 299, 2007.

70. MCGUINNESS M., MAZURKIEWICZ V., BRENNAN E., DOWLING D. Dechlorination of Pesticides by a Specific Bacterial Glutathione S-transferase, BphKLB400: Potential for Bioremediation. Eng. Life Sci. 7 (6), 611, 2007.

71. NJOKU V., ASIF M., HAMEED B. 2, 4-Dichlorophenoxyacetic acid adsorption onto coconut shell-activated carbon: isotherm and kinetic modeling. Desalin. Water Treat. 55 (1), 132, 2015.

72. BUKOWSKA B. Toxicity of 2, 4-Dichlorophenoxyacetic Acid-Molecular Mechanisms. Polish J. Environ. Stud. 15, 3, 2006.

73. LOOMIS D., GUYTON K., GROSSE Y., EL GHISSASI F., BOUVARD V., BENBRAHIM-TALLAA L., GUHA N., MATTOCK H., STRAIF K. Carcinogenicity of lindane, DDT, and 2, 4-dichlorophenoxyacetic acid. Lancet Oncol. 16, 891, 2015.

74. SCHLOSSER P.M., BALE A.S., GIBBONS C.F., WILKINS A., COOPER G.S. Human health effects of dichloromethane: key findings and scientific issues. Env. Health Persp. 123 (2), 114, 2015.
75. BALE A.S., BARONE S., SCOTT C.S., COOPER G.S. A review of potential neurotoxic mechanisms among three chlorinated organic solvents. Toxicol. App. Pharmacol. 255 (1), 113, 2011.

76. COOPER G.S., SCOTT C.S., BALE A.S. Insights from epidemiology into dichloromethane and cancer risk. Int. J. Env. Res. Pub. He. 8 (8), 3380, 2011.

77. BENBRAHIM-TALLAA L., LAUBY-SECRETAN B., LOOMIS D., GUYTON K.Z., GROSSE Y., EL GHISSASSI F., BOUVARD V., GUHA N., MATTOCK H., STRAIF K. Carcinogenicity of perfluorooctanoic acid, tetrafluoroethylene, dichloromethane, 1, 2-dichloropropane, and 1, 3-propane sultone. Lancet Oncol. 15, 924, 2014.

78. STOURMAN N.V., ROSE J.H., VUILLEUMIER S., ARMSTRONG R.N. Catalytic mechanism of dichloromethane dehalogenase from Methylophilus sp. strain DM11. Biochemistry. 42, 11048, 2003.

79. GISI D., WILLI L., TRABER H., LEISINGER T., VUILLEUMIER S. Effects of bacterial host and dichloromethane dehalogenase on the competitiveness of methylotrophic bacteria growing with dichloromethane Appl. Env. Microbiol. 64, 1194, 1998.

80. BLOCKI F., LOGAN M., BAOLI C., WACKETT L. Reaction of rat liver glutathione S-transferases and bacterial dichloromethane dehalogenase with dihalomethanes. J. Biol. Chem. 269, 8826, 1994.

81. KANKOTIA S., STACPOOLE P.W. Dichloroacetate and cancer: new home for an orphan drug? Biochimica et Biophysica Acta (BBA)-Reviews on Cancer 1846 (2), 617, 2014.

82. LI W., GU Y., JAMES M.O., HINES R.N., SIMPSON R.N., LANGAEE T., STACPOOLE P.W. Prenatal and postnatal expression of glutathione transferase $\zeta 1$ in human liver and the roles of haplotype and subject age in determining activity with dichloroacetate, Drug Metab. Dispos. 40, 232, 2012.

83. TONG Z., BOARD P.G., ANDERS M. Glutathione transferase zeta-catalyzed biotransformation of dichloroacetic acid and other $\alpha$-haloacids. Chem. Res. Toxicol. 11, 1332, 1998.

84. HE W., BAI Z.L., LIU W.X., KONG X.Z., YANG B., YANG C. Occurrence, spatial distribution, sources, and risks of polychlorinated biphenyls and heavy metals in surface sediments from a large eutrophic Chinese lake (Lake Chaohu). Env. Sci. Pollut. Res. 23 (11), 10335, 2016.

85. ZHENG T., HOLFORD T.R., TESSARI J., MAYNE S.T., OWENS P.H., WARD B., CARTER D., BOYLE P., DUBROW R., ARCHIBEQUE-ENGLE S. Breast cancer risk associated with congeners of polychlorinated biphenyls. Am. J. Epidemiolo 152, 50, 2000.

86. LEHMANN G.M., CHRISTENSEN K., MADDALONI M., PHILLIPS L.J. Evaluating health risks from inhaled polychlorinated biphenyls: research needs for addressing uncertainty. Environ. Health Persp. 123, 109, 2015.

87. WANG S., CHNG K.R.,WILM A., ZHAO S., YANG K.-L., NAGARAJAN N., HE J. Genomic characterization of three unique Dehalococcoides that respire on persistent polychlorinated biphenyls. PNAS. 111, 12103, 2014.

88. JARACZEWSKA K., LULEK J., COVACI A., VOORSPOELS S., KALUBA-SKOTARCZAK A., DREWS K., SCHEPENS P. Distribution of polychlorinated biphenyls, organochlorine pesticides and polybrominated diphenyl ethers in human umbilical cord serum, maternal serum and milk from Wielkopolska region, Poland. Sci. Total Environ. 372, 20, 2006. 
89. LAUBY-SECRETAN B., LOOMIS D., GROSSE Y., EL GHISSASSI F., BOUVARD V., BENBRAHIM-TALLAA L., GUHA N., BAAN R., MATTOCK H., STRAIF K. Carcinogenicity of polychlorinated biphenyls and polybrominated biphenyls. Lancet Oncolol. 14, 287, 2013.

90. LI M.C., CHEN P.C., TSAI P.C., FURUE M., ONOZUKA D., HAGIHARA A. Mortality after exposure to polychlorinated biphenyls and polychlorinated dibenzofurans: A meta-analysis of two highly exposed cohorts. Int. J. Cancer 137 (6), 1427, 2015.

91. TEHRANI R., VAN AKEN B. Hydroxylated polychlorinated biphenyls in the environment: sources, fate, and toxicities. Env. Sci. Pollut. Res. 21 (10), 6334, 2014.

92. FIEDLER H. National PCDD/PCDF release inventories under the Stockholm convention on persistent organic pollutants. Chemosphere. 67, 96, 2007.
93. ABRAHAM W.R., NOGALES B., GOLYSHIN P.N. PIEPER D.H., TIMMIS K.N. Polychlorinated biphenyldegrading microbial communities in soils and sediments. Curr. Opin. Microbiol. 5, 246, 2002.

94. AHUJA R., KUMAR A. Metabolism of DDT [1, 1, 1-trichloro-2, 2-bis (4-chlorophenyl) ethane] by Alcaligenes denitrificans ITRC-4 under aerobic and anaerobic condition. Curr. Microbiol. 46, 65, 2003.

95. HIRAOKA Y,. YAMADA T., TONE K., FUTAESAKU Y., KIMBARA K. Flow cytometry analysis of changes in the DNA content of the polychlorinated biphenyl degrader Comamonas testosteroni TK102: effect of metabolites on cell-cell separation. Appl. Environ. Microbiol. 68, 5104, 2002.

96. SEEGER M., PIEPER D. Genetics of biphenyl biodegradation and co-metabolism of PCBs. Handbook of hydrocarbon and Lipid Microbiology: Springer: USA, 1179, 2010. 